\title{
Evaluation of nanosilica emission in polydimethylsiloxane composite during incineration
}

\author{
G. Ounoughene ${ }^{\mathrm{a}, \mathrm{b}, \mathrm{c}}$, C. Chivas-Joly ${ }^{\mathrm{d}, *}$, C. Longuet ${ }^{\mathrm{b}}$, O. Le Bihan ${ }^{\mathrm{e}}, \mathrm{J}-\mathrm{M}$. Lopez-Cuesta ${ }^{\mathrm{b}}$, L. Le Coq ${ }^{\mathrm{a}}$ \\ ${ }^{a}$ LUNAM, Ecole des Mines de Nantes, GEPEA, CNRS, UMR 6144, 4 rue Alfred Kastler, 44307, Nantes Cedex 03, France \\ ${ }^{\mathrm{b}}$ Centre des Matériaux des Mines d'Alès (C2MA), Ecole des Mines d'Alès, 6 Avenue de Clavières, 30319, Alès Cedex, France \\ ${ }^{\mathrm{c}}$ ADEME, 20 avenue du Grésillé, 49004, Angers Cedex 01, France \\ ${ }^{\mathrm{d}}$ LNE, 29 Avenue Roger Hennequin, 78197, Trappes Cedex, France \\ ${ }^{\mathrm{e}}$ INERIS, Parc Technologique Alata, 60550, Verneuil-en-Halatte, France
}

Keywords:

Silicone

Incineration

Aerosol

Cone calorimeter

Tubular furnace

Nanoparticles

Environment

\begin{abstract}
A B S T R A C T
At the end of their life cycle, it is expected that many industrial silicone components end up in incineration waste plants. Hence, the issue concerning the risks resulting from the generation of fumes (combustion gas and aerosol) has to be addressed. The aim of our work was to investigate the behavior and fate of nanosilicas from filled polydimethylsiloxane nanocomposites burnt under two different scenarios of incineration. Combustion tests have been performed at lab-scale using a particular tubular furnace and a specific cone calorimeter. The collected fumes (particulate matter and gas phase) have been characterized using various techniques. The results show persistent nanosilica particles, newly produced nanosilica particles in the fumes and in the residues, as well as silicon oxycarbide $\mathrm{SixOyCz}$ particles which seem to originate from polysiloxane matrix decomposition.
\end{abstract}

\section{Introduction}

Nanocomposites have been widely studied and produced since the end of the nineties. These trendy materials containing nanomaterials represent approximately 20,000 metric tons per year [1]. This waste should be streamed to be recycled, placed in landfills or incinerated. Recently, few studies on the behavior and the fate of nano-objects in incineration facilities have been investigated at lab-scale [2] and at real scale [3].Various polymers have been studied, from paint where Massari et al. [4] suggest that $\mathrm{TiO}_{2}$ nanoparticles may undergo to physicochemical transformation during the incineration, and that titanium found in ashes stay in glass matrix. According to Derrough et al. [5], the most of the nanomaterials remained in the bottom ash and only a small amount partitioned into the particulate matter. At the same time, 
Vejerano et al. [6] [7],) showed that the combination of high specific surface area of nanomaterials might be responsible for affecting the formation of toxic pollutants during incineration. In parallel, Ounoughene et al. [8] investigated the behavior of various nanocomposites during incineration process and show that nanoparticles (NP) should be potentially transformed into other structures which were found in both the aerosol and the residues. The risks related to the potential toxicity of fine particles (e.g. during combustion processes) have already been outlined [9]. The review of the bibliography related to the incineration of filled polymer highlights the lack of studies concerning silicone incineration (excepted, a recent paper on characterization of waste containing nanofillers [10]. They focus only on solid form and don't present an overview of the fate of nanoparticles. The originality of this study lies in the fact that silicones are crosslinked materials and not recyclable and the only issues remains incineration or landfilling [11] and that the thermal degradation of silicone induces silica formation. The limited presence of incineration behavior of nanosilica filled polydimethylsiloxane in published literature has prompted this investigation. These widely used polymers have many industrial and domestic applications such as household and personal care products, textile treatments, electrical cables and wires [12,13]. As a consequence of their widespread use, many end-of-life polysiloxanes components are likely to be sent to municipal waste incineration plants. Polysiloxanes can enter a waste incineration plant in two different ways: (1) solid waste silicones are converted back to inorganic substances, mainly, amorphous silica and carbon dioxide (polysiloxanes can also be landfilled), (2) liquid waste from sludge (resulting from products such as shampoos or detergents) which ends up in municipal wastewater [12]. However, only few studies focus on the silica produced during the combustion of polysiloxanes. In biogas industries, problems have been reported regarding silica particles generated during the combustion of biogas containing siloxane traces. Indeed, the deposition of these particles in the combustion chamber causes dysfunction of engines and turbines [14-16]. To our knowledge, apart from this last issue, studies dealing with silica particles (mainly submicron particles) released from combustion of polysiloxanes are scarce. Hence, further investigations about fumes (combustion gas and aerosol) produced during the combustion of polydimethylsiloxanes are required. Polydimethylsiloxane (PDMS) is the main commercial polysiloxane. It is a synthetic polymer with $\mathrm{Si}-\mathrm{O}$ backbone and methyl side groups. It exhibits interesting properties like hydrophobic characteristics [17], superior properties of heat and cold resistance, excellent weather resistance and electrical properties [18]. Thermal degradation of PDMS leads to a silica residue or a silicon oxycarbide residue depending on combustion conditions [19-21]. Furthermore, in order to improve their mechanical properties, PDMS are often reinforced with nanoparticles like amorphous silica $[19,22]$ which can be divided into manufactured products and natural minerals (like diatomaceous earth). Synthetic amorphous silica (SAS), especially nanosized silica (with a diameter $<100 \mathrm{~nm}$ ), has received huge attention towards many industrial applications for several years. Even if, many aspects related to the size and porous texture of these nanomaterials have raised in the literature. That concerns mainly safety since human exposure to SAS and environmental release [23,24]. However, papers regarding risks assessment in link with the incineration end-of life deals rarely with the impact of particles size after thermal degradations.

The thermal degradation of nanosilica filled PDMS was studied by different authors $[19,21,25]$ and it was shown that nanosilica particles decrease the flammability of PDMS. However, the fumes produced during the thermal degradation were never investigated, and tests involving the combustion parameters of domestic waste incineration (temperature around $850^{\circ} \mathrm{C}$, highly ventilated combustion, at least $2 \mathrm{~s}$ residence time for the combustion gas in a post-combustion chamber at $850^{\circ} \mathrm{C}$, and high oxygen/fuel contact) were never reported. Here again, there is a lack in the literature regarding silica particles behavior during combustion, especially during incineration.
For the first time, the present study brings an insight about silica particles generated by the combustion (under two incineration scenarios) of a silica/PDMS nanocomposite. The authors suggest the use of two small scale combustion devices with controlled key incineration parameters: a modified tubular furnace and a modified cone calorimeter to access of PN (particle number) by combining physical one-line characterization [8] and particles sampling (morphological analysis). The fumes were sampled downstream of the combustion devices (downstream of the post-combustion chamber is considered as equivalent to the upstream of fumes treatment sections in a real-scale incineration plant), and were characterized using various aerosol and gas analysis techniques. The solid combustion residues were analyzed as well. The aim of this work was (i) to study the behavior and fate of silica particles when a silica/PDMS nanocomposite is incinerated, (ii) to simulate and to compare the results of two experimental setups devoted to incineration at lab scale (tubular furnace and cone calorimeter with controlled atmosphere). This study also investigated possible modifications affecting nano-silica particles undergo during their stay in the incinerator furnace chambers, and where they could be potentially released.

\section{Methodology}

Two experimental setups were used in order to carry out incineration tests and to track effluents (particles and smoke). Two lab-scale devices (tubular furnace and cone calorimeter) were improved and adapted to simulate incineration, in accordance with the $4 \mathrm{~T}$ (Temperature, Time, Total amount of $\mathrm{O}_{2}$ and Turbulance) rules [26]:

- Temperature $\left(850^{\circ} \mathrm{C}\right)$

- Time (2s)

- Total amount of Oxygen ( $>11 \%)$

- Turbulence (a good mix between combustible and oxygen)

This section aims to compare these two devices to ensure the key incineration parameters are under controlled.

\subsection{Sample's description and formulations}

The sample is a nanosilica filled polydimethylsiloxane. It consists of a PDMS gum (68.5 wt\%), a siloxane oil (3wt\%, PDMS-SiOH) and nanosized fumed amorphous silica particles $(27 \mathrm{wt} \%)$ with an average primary particle size of $12 \mathrm{~nm}$. PDMS was mixed with a 2,4 dichlorobenzoic catalyst (used as radical generator necessary to cross linked the matrix) and thermo-compressed using a Darragon type 3 press in $10 \times 10 \times 0.4 \mathrm{~cm}^{3}$ steel square (at 30 sheets, $115^{\circ} \mathrm{C}$ during $8 \mathrm{~min})$. A pristine PDMS is also tested for comparison, when needed. $0.25 \mathrm{~g}$ samples $\left(1 \times 1 \times 0.2 \mathrm{~cm}^{3}\right)$ from these specimens were cut and then tested in the incineration scenario 1 (tubular furnace) and $2.5 \mathrm{~g}$ $\left(2.5 \times 2.5 \times 0.4 \mathrm{~cm}^{3}\right)$ were tested in the incineration scenario 2 (cone calorimeter).

\subsection{Lab-scale incinerator devices and analyses}

A tubular horizontal furnace (Carbolite STF 15/610) [2] and a cone calorimeter (Fire Testing Technology) [26] were modified to simulate conditions implemented in an industrial grate incinerator. As illustrated in Fig. 1, the sample holder is considered as the "combustion chamber" where the temperature is maintained at $850^{\circ} \mathrm{C}$ (at least) for the tubular furnace and where the thermal flow is settled at $75 \mathrm{~kW} / \mathrm{m}^{2}$ (which corresponds to a temperature close to $850^{\circ} \mathrm{C}$ ) in the cone calorimeter. Air cross flows penetrate and mix with the combustibles. Then, the "post-combustion chamber" is the chamber zone where the fumes continue their oxidation (during $2 \mathrm{~s}$ for the tubular furnace; during $0.2 \mathrm{~s}$ for the cone calorimeter). Finally, it is conveyed to the measurement lines described as follows. 


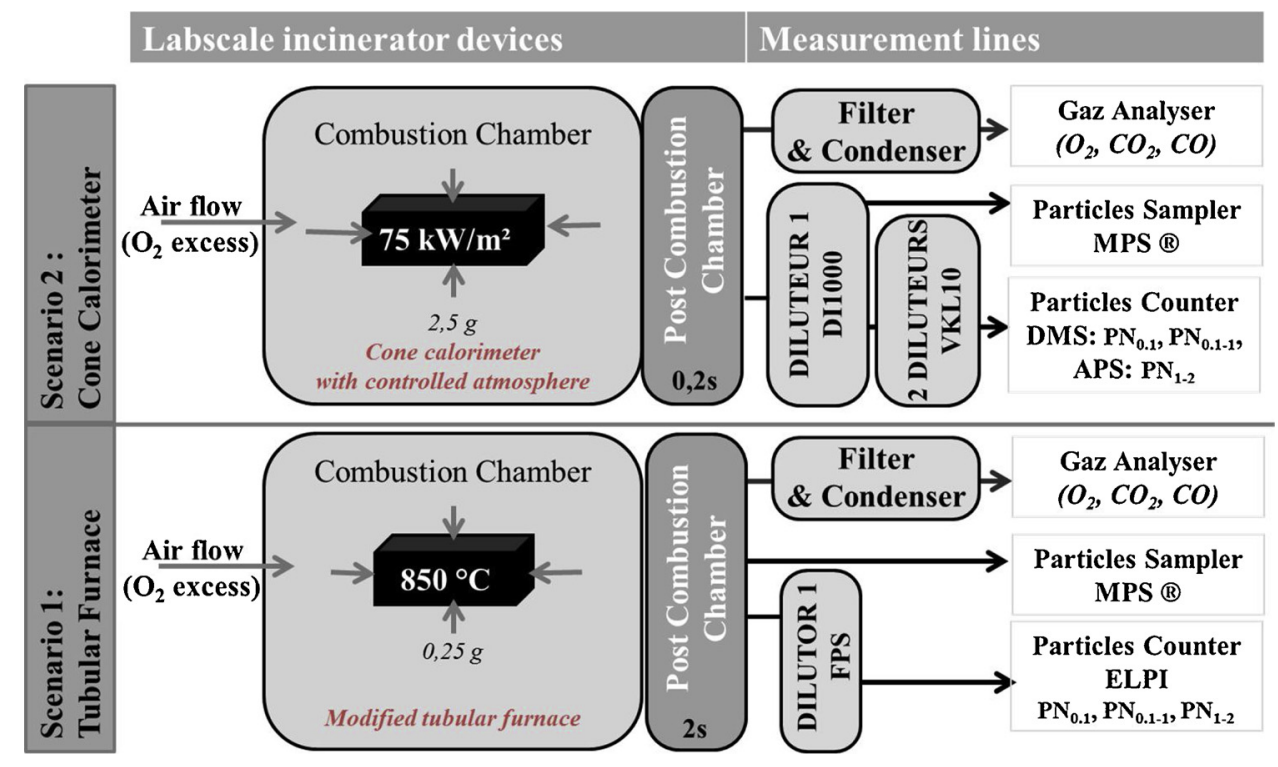

Fig. 1. Basic diagram of the two experimental setups (incinerator devices with measurement lines).

In order to superimpose the curves of time tracking and to synchronize all events detected, it is important to know the response time of each measurement line. It was determined by stopwatch (an uncertainty of two seconds was taken into account).

The fumes were sampled appropriately as explained below and analyzed in two different ways:

- time tracking for the gas and particles concentration from the fumes, - off-line analysis for the morphology and chemical composition of particles.

Further analyses were conducted on the combustion solid residues (see below, Section 2.2.4).

\subsubsection{Time tracking for the gas phase}

The sampling of the gas phase from the fumes followed the methods used for sampling direct emissions from stationary combustion sources. For both devices, the fumes were dried and filtered using a line with a hot filter and a condenser. Multi-gas analyzers were used (PG-250 Horiba portable gas analyzer for the tubular furnace and Servomex 4100 gas analyzer for the cone calorimeter) to determine the evolution of the combustion gases concentrations: consumption of $\mathrm{O}_{2}\left(\%_{\mathrm{vol}}\right)$, production of $\mathrm{CO}_{2}\left(\%_{\mathrm{vol}}\right)$ and $\mathrm{CO}\left(\mathrm{ppm}_{\mathrm{vol} .}\right)$.

\subsubsection{Time tracking for particle number concentration}

The fumes sampled have to be representative of the aerosol upstream the flue-gas cleaning systems, i.e. downstream of the postcombustion chamber. For the two devices, the target temperature is 150 $( \pm 10){ }^{\circ} \mathrm{C}$. Actually, for industrial conditions, the flue gas leaves the post-combustion chamber and goes through a heater (for heat recovery purpose) and then flows through a treatment process at a temperature around $150( \pm 10){ }^{\circ} \mathrm{C}$ in accordance with BREF Waste Incineration (2006) [27]. For each scenario, two different samples and counters were used to conduct the analysis with respect to the temperature constraint mentioned above.

2.2.2.1. Incineration scenario 1: tubular furnace device. Regarding the tubular furnace scenario, an Electrical Low Pressure Impactor (ELPI, Dekati) was used downstream of a FPS dilutor (Fine particle sampler, Dekati). As explained in a previous study [19], the objective of the sampling was to avoid cold spots below $150( \pm 10){ }^{\circ} \mathrm{C}$ during the first dilution and then thermophoretic losses can be prevented by heating the sampling probe to same or higher temperature than sample temperature. The FPS dilutor performed two successive dilutions: the first heated dilution at $150( \pm 10){ }^{\circ} \mathrm{C}$ and the second at room temperature. Thus, the sampled fumes underwent two dilutions with a total factor of 1:30. The ELPI provided a real-time measurement of particle number concentration through 12 channels from $17 \mathrm{~nm}$ to $5 \mu \mathrm{m}$ (aerodynamic diameter of sphere-like particles) [28].

2.2.2.2. Incineration scenario 2: cone calorimeter device. Regarding the cone calorimeter device, an APS spectrometer (TSI, Aerodynamic Particle Sizer 3321) and a DMS 500 spectrometer (Cambustion M85, Fast particle analyser, Dynamic particle spectrum) were used downstream of two dilution stages: a first hot dilution with a DI1000 dilutor (Dekati) with a 1:10 dilution ratio followed by two VKL10 dilutors (Palas) with a 1:100 dilution ratio. Similarly to the scenario 1, the first dilution was heated at $150( \pm 10){ }^{\circ} \mathrm{C}$ in order to avoid cold spots and the second dilution was at room temperature. Thus, the sampled fumes underwent three dilutions with a total theoretical factor of 1:1000. The DMS500 and the APS provided a real-time measurement of particle number concentration respectively from $5 \mathrm{~nm}$ to $1 \mu \mathrm{m}$ (electrical mobility diameter of sphere-like particles) and from 1 to $2 \mu \mathrm{m}$ (aerodynamic diameter of sphere-like particles) [29-31].

The $\mathrm{PN}_{\mathrm{x}-\mathrm{y}}$ are defined as the number concentration of particles counted by the ELPI, the APS and the DMS500 with mean geometric diameter (Di) between $\mathrm{x}$ and $\mathrm{y} \mu \mathrm{m}$.

A previous study [32] have shown that the three counters from the measurement lines indicate different diameters (aerodynamic diameters for ELPI and APS, electrical mobility diameters for DMS) since they use different techniques to count particles. So, it must be borne in mind that the diameters are not equivalent.

\subsubsection{Off-line analysis for particulate matter}

Regarding off-line analyses, fumes and particles were collected over a targeted time range on a TEM grid with a MPS ${ }^{\circ}$ (Mini-ParticleSampler, Ecomesure [33]). It was a $10 \mathrm{~s}$ sampling downstream of the tubular furnace and downstream of the first dilution stage for the cone calorimeter, as presented on Fig. 1. A Philips CM12 TEM $200 \mathrm{kV}$ was used for the imagery.

\subsubsection{Analysis of the combustion residues}

The combustion solid residues contained in the sample holder of the lab-scale incinerators were collected after each test. They were 
analyzed by scanning electronic microscope (SEM, JEOL 7600F High Resolution Analytical SEM energy dispersive spectrometer SDD BRUKER (EDS) X-ray detector), by X-Ray Diffraction (XRD) with a Bruker AXS D8 Advance diffractometer using $\mathrm{Cu} \mathrm{K} \alpha$ radiation, and by a Bruker Optics IFS 66 series FT-IR spectrometer.

\subsubsection{Standard cone calorimeter test}

A Cone Calorimeter from FTT (United Kingdom), according to the standard ISO 5660, has been used in order to measure the HRR (heat rate release) and the mass loss during the tests. The heat flux was fixed to $75 \mathrm{~kW} / \mathrm{m}^{2}$ and sample size to $100 \times 100 \times 4 \mathrm{~mm}$. Ignition was piloted using a spark igniter. At least two samples were tested for each formulation and reproducibility was considered as satisfactory. The uncertainty on main values is considered around $15 \%$.

\section{Results and discussion}

Incineration experiments were performed through both scenarios. The time tracking results gave information on the thermal decomposition of the nanocomposite and imagery techniques on the morphology of the fumes particles. Besides, the analysis of residues brought supplementary information on the fate and the behavior of silica particles.

\subsection{Time tracking of gas concentration and particle number concentration}

The graphs showing the evolution of concentrations of different gases during the two incineration scenarios of the nanocomposite are given in Fig. 2. The averages of three runs are presented with the associated standard deviation.
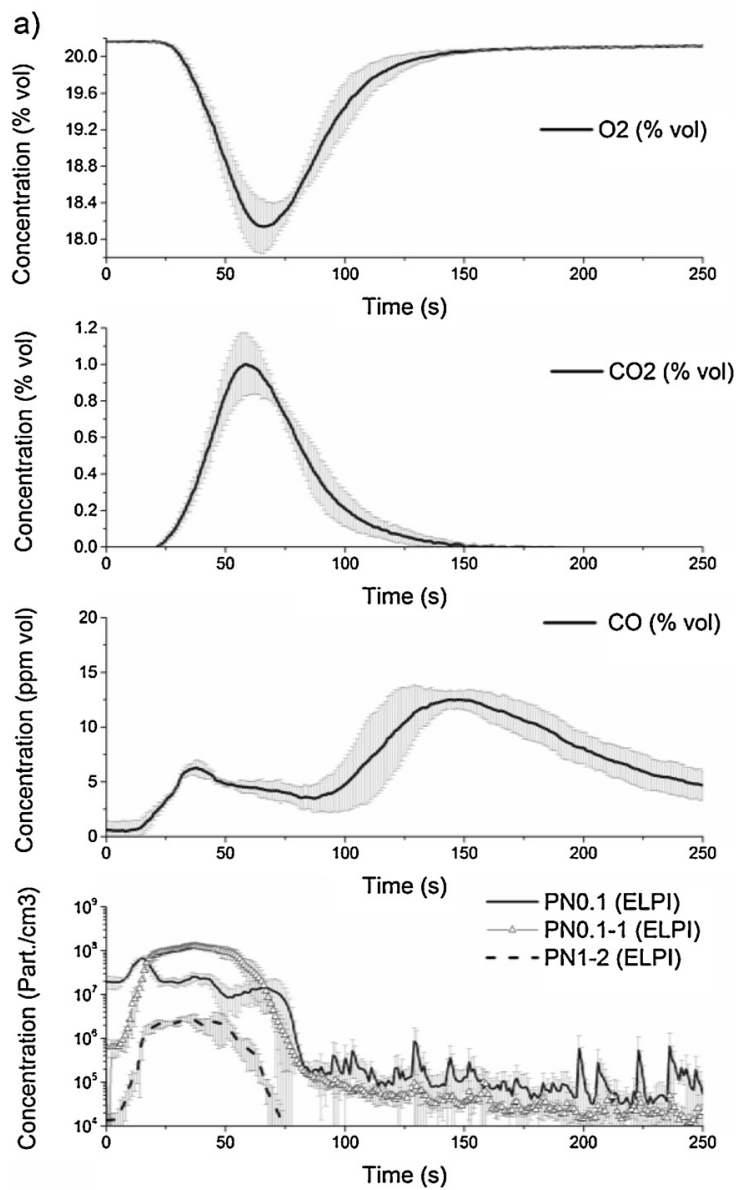

The first observation is a rather good agreement of time tracking results for the two incineration scenarios. Despite the differences in the amount of samples tested in the combustion devices $(0.25 \mathrm{~g}$ for tubular furnace versus $2.5 \mathrm{~g}$ for cone calorimeter) and in the setups of measurement lines used, close tendencies were observed.

Indeed, regarding the gas time tracking, the dioxygen $\left(\mathrm{O}_{2}\right)$ consumption is symmetrical to the carbon dioxide $\left(\mathrm{CO}_{2}\right)$ production for both cases. Also, the production of carbon monoxide (CO) follows a two-step mechanism with a first slight emission followed by a larger emission when the $\mathrm{CO}_{2}$ is decreasing, in both cases.

Besides, the flame appears at $\mathrm{t}=30 \mathrm{~s}$ and disappears at $\mathrm{t}=125 \mathrm{~s}$, in the case of the cone calorimeter scenario (for which the flame can be observed through a window). Then, according to the Fig. $2 \mathrm{~b}$, the two step mechanism mentioned above can be related to the ignition phenomenon. Actually, when the flame appears, the temperature in the post-combustion chamber increases and reaches around $1000{ }^{\circ} \mathrm{C}$ (according to the thermocouple situated in the post-combustion chamber between the surface of the sample and the base of the cone calorimeter). During this elevation of temperature, $\mathrm{O}_{2}$ is consumed, $\mathrm{CO}_{2}$ and particles $\left(\mathrm{PN}_{0,1}\right.$ and $\left.\mathrm{PN}_{0,1-1}\right)$ are emitted significantly while $\mathrm{CO}$ is very slightly produced. Thus, this first phase could represent a complete combustion whereas the second phase could represent an incomplete combustion during which $\mathrm{CO}$ is highly emitted, little $\mathrm{CO}_{2}$ is produced and hardly any $\mathrm{O}_{2}$ is consumed. The temperature also decreases during this phase. Furthermore, this behavior can be explained by the decomposition pathway of PDMS material. Actually, this nanocomposite can be considered as an "intumescent" material because it swells when it is submitted to a heat source and because a silica protective layer appears on its surface [19]. Thus, the silica layer acts as a barrier

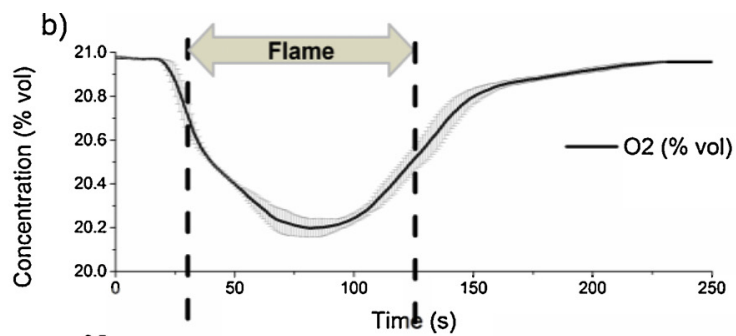

b)
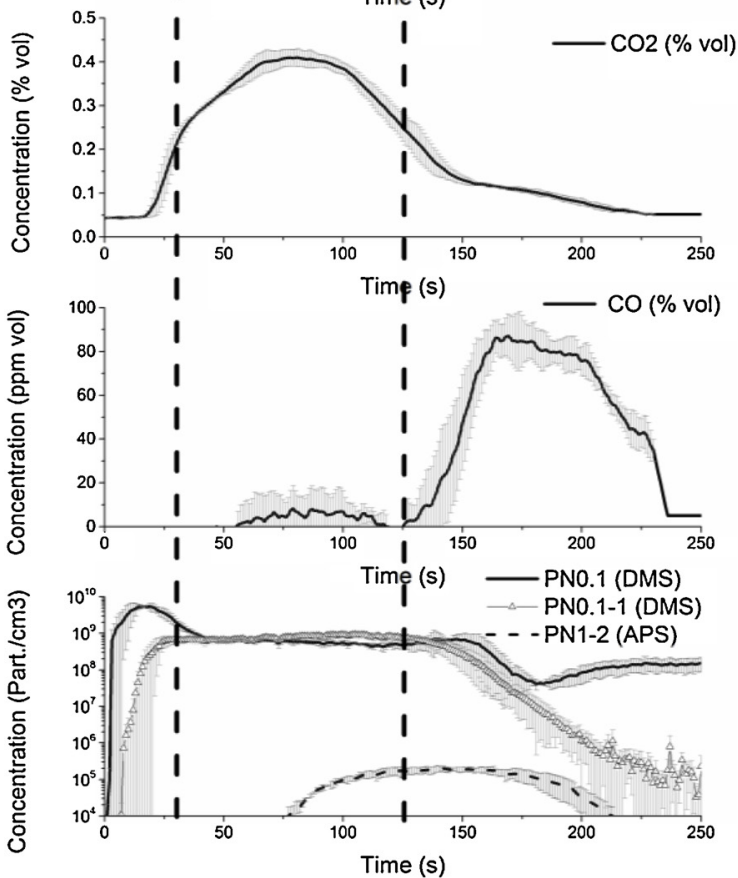

Fig. 2. Time tracking of gas concentration and particle number concentration from filled PDMS (a) Incineration Scenario 1: Tubular furnace - (b) Incineration Scenario 2: Cone calorimeter. 
limiting mass and heat transfers. In this way, the two step mechanism observed could be related to the silica layer evolution during the combustion. After the ignition, the progressive swelling of the material and the formation of a white layer on the surface with a complete combustion can be observed. Then, after the extinction, this layer protects the remaining combustible material from oxygen. In this way, the oxidation cannot be completed. This would explain why CO predominates over $\mathrm{CO}_{2}$ during this second step.

Regarding the particles time tracking, for $\mathrm{PN}_{0,1}$ (i.e particles with diameter $<100 \mathrm{~nm}$ ), for both scenarios, they are released even before the ignition, due to pyrolysis of PDMS and de-cohesion of silica particles from the polymer matrix during the degradation. They are predominant after the beginning of combustion because of the formation of the barrier layer and the swelling of the material. Then, they decrease in favor of $\mathrm{PN}_{0,1-1}$ (i.e. particles with diameter $100 \mathrm{~nm}<\mathrm{Di}<1 \mu \mathrm{m}$ ). During the combustion stage (Fig. 2b), the production of both categories of particles is quasi-constant. As for $\mathrm{PN}_{1-2}$ (i.e. particles with diameter $1 \mu \mathrm{m}<\mathrm{Di}<2 \mu \mathrm{m}$ ), these particles appear later in the combustion process and they are relatively less abundant. It can be explained by the temperature reached during the flame (around $1100{ }^{\circ} \mathrm{C}$ ), which is able to initiate sintering of silica particles [34].

Additionally, it can be observed that the concentration of particles released is high and that agglomeration of these particles in the furnace is highly likely. However, it would be difficult to ensure if these phenomena occur in a real scale industrial furnace, given the size limits of the lab scale devices. Furthermore, the noticeable $\mathrm{PN}_{0,1}$ trail in the end of the combustion, for both cases (but more accentuated for the second scenario with the cone calorimeter) can be explained on the one hand by a thermophoresis phenomenon in the measurement line; and on the other hand by the glowing of the solid residue (described hereinafter) which would be dragged by the air flow.

\subsection{Imaging and $X$-ray microanalysis}

The results from image analysis provide only qualitative considerations.

\subsubsection{Fumes particles}

For both scenarios, imaging on combustion particles collected on TEM grids reveals the presence of submicronic aggregates and agglomerates. The primary particles of these structures exhibit different sizes: nanoparticles $(\mathrm{D}<100 \mathrm{~nm})$ and ultrafine particles (D $>100 \mathrm{~nm}$ ) (Figs. 3 and 4 ).

The terms primary particles, aggregates and agglomerates are defined as follows: primary particles are the smallest identifiable individual particles, aggregates are primary particles contacting each other at surfaces or edges and they cannot be broken down, while agglomerates are particles witch can be severed or aggregates contacting each other but severable [22,35,36].

(a)

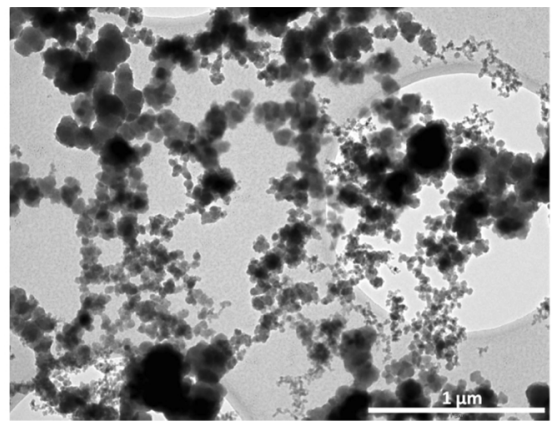

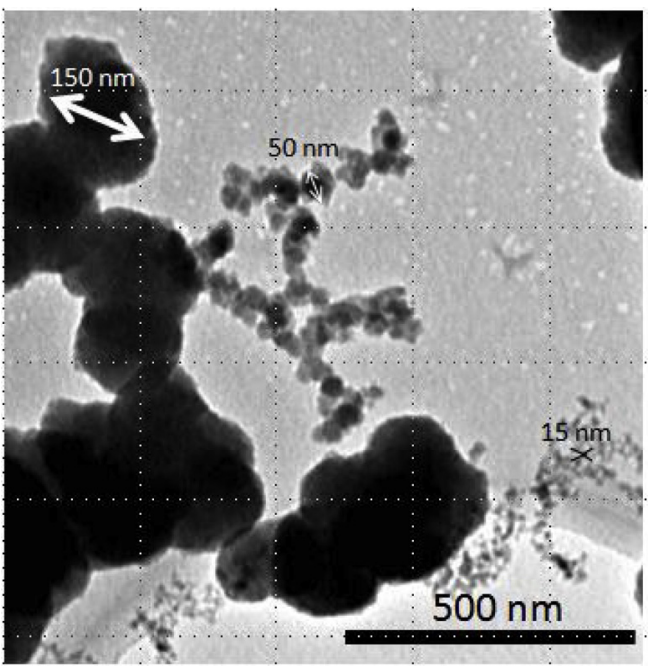

Fig. 4. Example of aggregates/agglomerates from fumes issued of filled PDMS 3 sizes of silica primary particles.

- Regarding aggregated nanoparticles, their diameter varies from $15 \mathrm{~nm}$ for the smallest particles to $50 \mathrm{~nm}$ for the largest. Their structures are chain-like and strung together like a fractal pearl. The size of aggregates varies from 100 to $500 \mathrm{~nm}$. It should be noted that the silica used as fillers in PDMS has a bimodal population (around $10 \mathrm{~nm}$ and $40 \mathrm{~nm}$ ).

- Regarding ultrafine particles, the primary particles are roughly spherical and their structures of about $1 \mu \mathrm{m}$ size are also chain-like but the network seems more compact.

$\mathrm{X}$-ray microanalysis shows the $\mathrm{Si} / \mathrm{C} / \mathrm{O}$ ratios of these particles (Fig. 5). The finest primary nanoparticles $15 \mathrm{~nm}$ contains mainly silicon and oxygen, which corresponds to silica composition, despite the $\mathrm{Si} / \mathrm{O}$ ratio is not accurate. The fine primary particles $(>100 \mathrm{~nm})$ and the biggest nanoparticles $(50<\mathrm{D}<100 \mathrm{~nm})$ contain $\mathrm{Si}, \mathrm{C}$ and $\mathrm{O}$ elements. According to the literature, these compounds with this type of composition should correspond, partially, to silicon oxycarbides $\left(\mathrm{Si}_{\mathrm{x}} \mathrm{O}_{\mathrm{y}} \mathrm{C}_{\mathrm{z}}\right)[20,21,37]$.

\subsubsection{Solid combustion residues}

The Fig. 6 shows the meringue-like residue resulting from the combustion in the cone calorimeter (scenario 2). It reveals an "intumescent" behavior of the material which has swollen during the thermal decomposition. The same meringue-like residue is observed for scenario 1 as well.

Heat Release rate (HRR) and mass loss values of the silica filled PDMS as well as these of a pristine PDMS were registered and are presented Fig. 7a and b. It can be noticed that the presence of silica does not affect the value of the HRR peak, nevertheless the combustion is

(b)

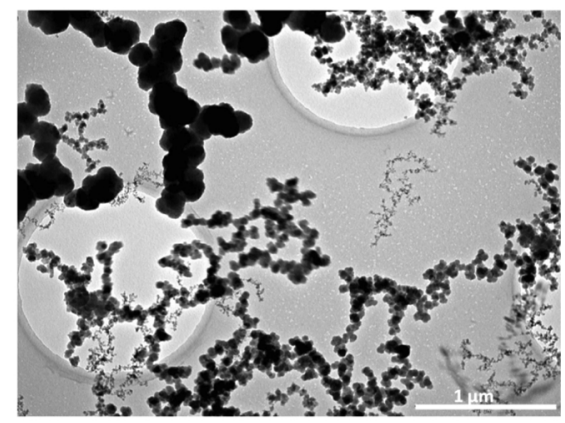

Fig. 3. Particles collected on TEM grids from filled PDMS (a) Incineration Scenario 1 (tubular furnace, $t=[30,40]$ s) and (b) Incineration Scenario 2 (cone calorimeter, $\mathrm{t}=[50,60] \mathrm{s})$. 

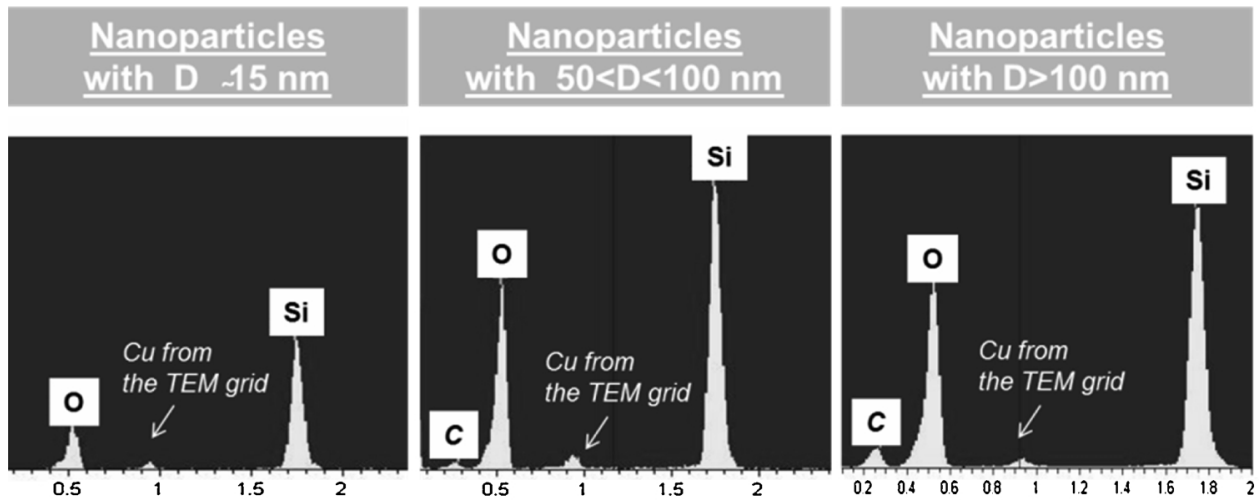

Nanoparticles with $D \sim 15 \mathrm{~nm}$

\begin{tabular}{ccc} 
Si (\% atomique) & O (\% atomique) & C (\% atomique) \\
\hline 70 & 30 & 0 \\
55 & 42 & 3 \\
56 & 36 & 8
\end{tabular}

Nanoparticles with $50<\mathrm{D}<100 \mathrm{~nm}$

36

Fig. 5. X-ray microanalysis on fumes particulate matter from filled PDMS.

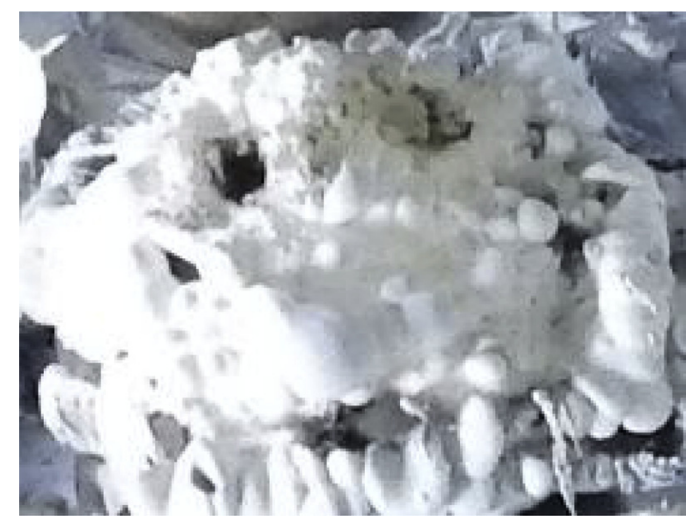

Fig. 6. Picture of the meringue-like solid residue of filled PDMS from initial sample of $100 \times 100 \times 4 \mathrm{~mm}$.

shorter in presence of silica. Consequently, the presence of silica seems to change the PDMS decomposition, despite the formation of a charred structure. PDMS degradation induced release of cyclo-siloxane gases in addition to silica. These gases promote expansion of the structure and also the generation of an intumescent layer.
Similarly, the final residue is obtained at a lower time for the filled PDMS. Moreover, the difference in the weight residue is lower (20\%) than the initial loading of silica in the filled PDMS (27\%) (Fig. 7b). Actually, pristine PDMS presents $40 \mathrm{wt} . \%$ residue at the end of the test and filled PDMS 60 wt.\% in the same conditions. It can be suggested that a part of the silica initially incorporated is released in the aerosol or the presence of silica changes the degradation mechanism of PDMS and decrease the formation of silica.

SEM (coupled with X-ray microanalysis) performed on combustion residues reveals that the residues seem to consist of aggregates and agglomerates with three sizes of primary particles (Fig. 8): the finest nanoparticles $(\mathrm{D}<15 \mathrm{~nm})$, the intermediate nanoparticles $(50<\mathrm{D}<100 \mathrm{~nm})$ and the biggest ultrafine particles (D $>100 \mathrm{~nm})$.

XRD performed on solid residues (from both incineration scenarios) showed that the residue is amorphous.

FTIR performed on solid residues (from both incineration scenarios) showed $\mathrm{Si}-\mathrm{O}-\mathrm{Si}$ bond $\left(1033 \mathrm{~cm}^{-1}\right)$ and $\mathrm{Si}-\mathrm{O}-\mathrm{C}$ bond $\left(813 \mathrm{~cm}^{-1}\right)$ [20] (Supporting information).

According to FTIR analysis and semi-quantitative X-ray microanalysis, this expanded residue from $\mathrm{PDMS} / 27 \mathrm{SiO}_{2}$ decomposition consists of silica and silicon oxycarbide $\left(\mathrm{Si}_{\mathrm{x}} \mathrm{O}_{\mathrm{y}} \mathrm{C}_{\mathrm{z}}\right)$.
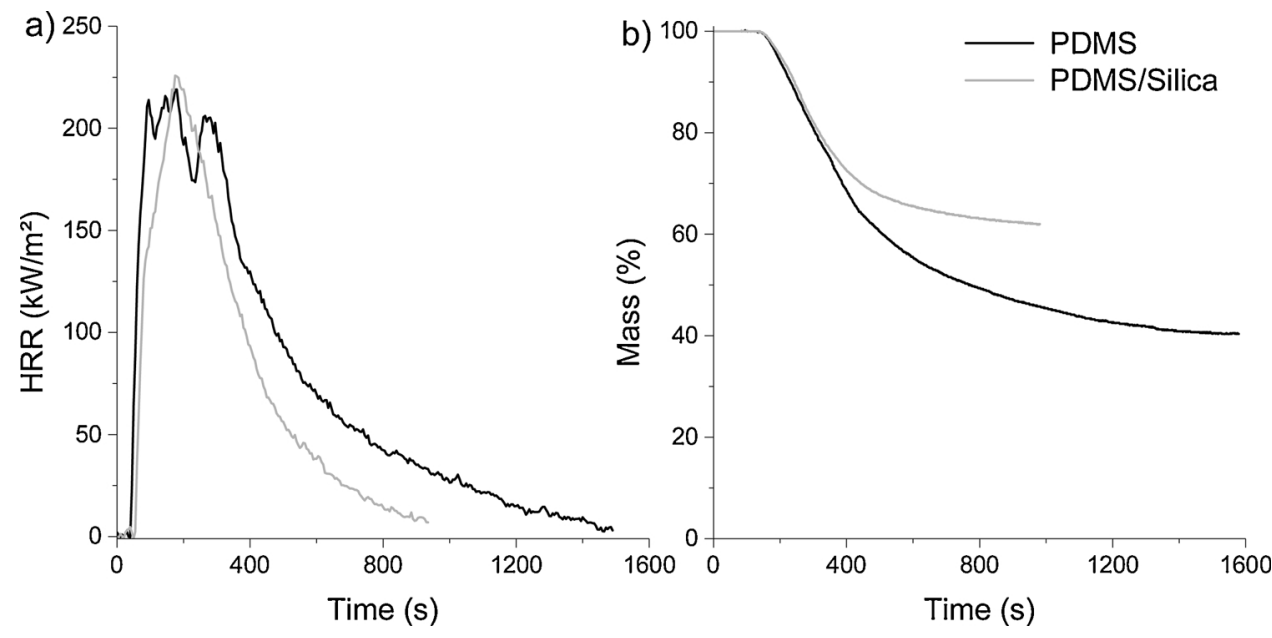

Fig. 7. Standard Cone Calorimeter test. a) HRR measurement vs time - b) Mass lost during the tests. 
(a)

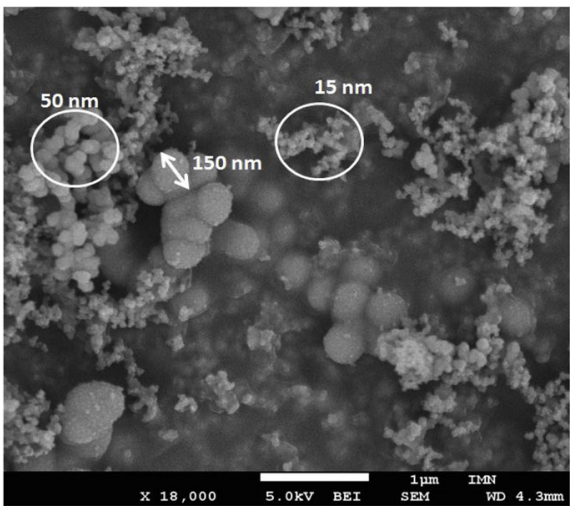

(b)

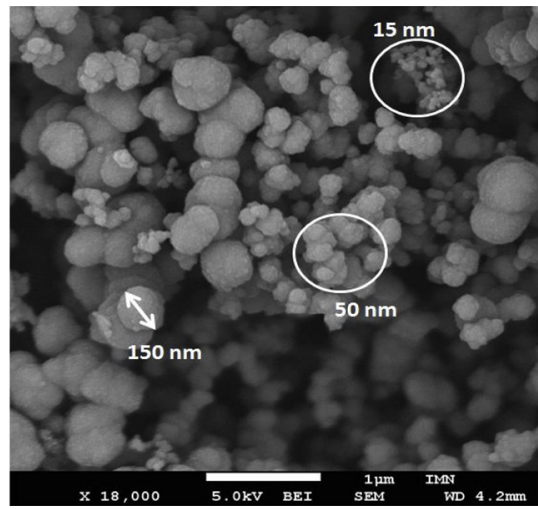

Fig. 8. SEM on residues from filled PDMS. (a) Incineration scenario 1 - (b) Incineration scenario 2.

\subsubsection{The origin of particles}

The origin of the particles observed in residues and in aerosol was scrutinized. Actually, since the tested nanocomposite consists of PDMS and nanosilica particles (about $12 \mathrm{~nm}$ ), the observed particles could come from the PDMS thermal decomposition or from the initially incorporated nanosilica particles. The determination of the origin seems difficult because the PDMS can produce silica and silicon oxycarbide via bonds reorganization under high heat rate, as shown in the literature [19-21]. Then, in order to attempt to assign the origin of each type of particles, the particles generated during the combustion of a virgin PDMS (pristine, without nanosilica) were observed (Fig. 9). The residues consist of aggregated/agglomerated fine particles (primary fine particles $>100 \mathrm{~nm}$ ). The aerosol contains aggregated/agglomerated fine particles and nanoparticles: the finest primary nanoparticles around $15 \mathrm{~nm}$, the intermediate primary particles between 50 and $100 \mathrm{~nm}$, and the biggest primary particles $>100 \mathrm{~nm}$ ). The X-ray microanalysis shows the presence of $\mathrm{Si}, \mathrm{C}$ and $\mathrm{O}$, but only median and bigger silica particles contain carbon. Hence, this suggests that these last kinds of silica result mainly from the decomposition of PDMS.

Both for filled PDMS and pristine PDMS, three sizes of particles are observed in the aerosol: the finest $\mathrm{D} \sim 15 \mathrm{~nm}$, the intermediate $50<\mathrm{D}<100 \mathrm{~nm}$, and the biggest particles $>100 \mathrm{~nm}$.

The finest primary nanoparticles $(15 \mathrm{~nm})$ could come from the initially incorporated nanosilica but also from the thermal decomposition of PDMS, in the case of the filled PDMS. Emission of smallest primary nanoparticles is difficult to be determined unambiguously. The other particles may come from the decomposition of the polydimethylsiloxane matrix and/or from the re-organization via agglomeration/aggregation and possibly sintering of newly produced particles and initially present nanoparticles.

(a)

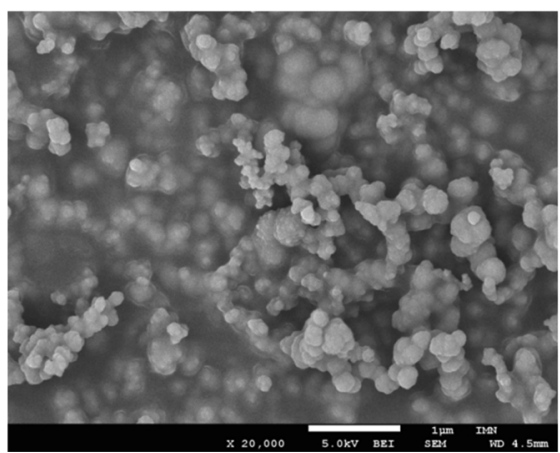

\section{Conclusion}

By means of two different experimental set-ups, it has been shown that the incineration of a nanosilica filled polydimethylsiloxane releases silica nanoparticles. Indeed, regarding its melting point (around $1700{ }^{\circ} \mathrm{C}$ [38]), silica cannot be destroyed after an incineration process and it remains intact.

This study highlights that silica is a persistent product of the incineration of a nanosilica filled polydimethylsiloxane. Thus, it can enter the environment through incineration outflows and can raise concerns during slags and fumes treatments as well.

Therefore, it seems relevant to determine how silica nanoparticles could act on health and ecosystem.

Even if amorphous silica is not involved in progressive fibrosis of the lung and it is less dangerous than the crystalline silica (which is known for its inflammogenic, fibrogenic and carcinogenic activities [23]), at high doses amorphous silica may result in acute pulmonary inflammatory responses.

Furthermore the nanosize of the silica makes it a potential danger. Many aspects related to the size of these nanomaterials have raised concerns about safety. As primary silica particles are generally nonisolated, some researchers consider that amorphous nanosilica particles are not harmful $[24,39]$. Besides, other researchers assert that even if nanosilica particles do aggregate, their specific area is the key parameter of their potential toxicity $[23,40]$. Indeed, their surface can interact with the biological environment, so in this way, the size and surface physico-chemical features of these nanoparticles contribute decisively to their biological effects

Thus, more detailed toxicity studies are required in order to supplement the existing data and to clearly identify the nanosilica health hazards.

The time tracking results revealed the barrier effect of silica particles in the polydimethylsiloxane matrix for both scenarios through a

(b)

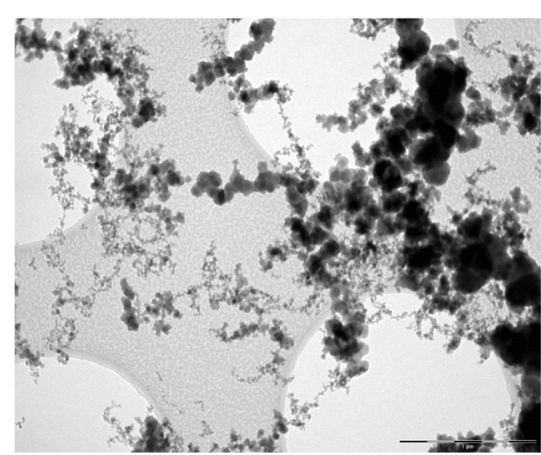

Fig. 9. Particles from pristine PDMS incineration in the cone calorimeter (scenario 2). (a) Combustion residues particles by SEM - (b) Combustion aerosol particles by TEM. 
two-step mechanism. Despite clear differences in the experimental setup: in the measurement line as well as in the combustion chambers (i.e., the way the sample is heated and the residence time of combustion gases), we obtain convergent results which indicates that the filled PDMS decomposes in the same way regardless of the incineration scenario.

In addition, the results showed a persistence of the incorporated nanosilica particles and a production of nanosilica and silicon oxycarbide (SixOyCz) in the fumes and in the solid residues. The primary particles are aggregated/agglomerated and they present three different sizes: around $15 \mathrm{~nm}$, between 50 and $100 \mathrm{~nm}$, and $>100 \mathrm{~nm}$. The finest particles could result, at least partially, from the silica introduced initially in the PDMS and from the PDMS decomposition as well. The biggest particles seem to come from to PDMS decomposition, due to the presence of carbon shown by X-microanalysis. The origin of the middle size particles, $50 \mathrm{~nm}<\mathrm{D}<100 \mathrm{~nm}$, is not clearly identified. These particles could originate either from filled silica or from the PDMS decomposition, as well as a combination of both. The substitution of silica with isotropic silica can provide an interesting study for the future.

\section{Conflict of interest}

The authors declare that they have no conflict of interest.

\section{Acknowledgements}

Financial support for this work was provided by ADEME, INERIS and LNE (Grant number 1106C0026).

The authors are grateful to their colleagues from INERIS, LNE, Trédi (Séché Environnement), C2MA (Centre des Matériaux des Mines d'Alès) and GEPEA (Mines Nantes), for their advice and technical support. Special thanks go to N. Stephant and O. Aguerre-Chariol for their respective contributions to SEM and TEM imaging.

\section{References}

[1] A.A. Keller, A. Lazareva, Predicted releases of engineered nanomaterials: from global to regional to local, Environ. Sci. Technol. Lett. 1 (1) (2014) 65-70.

[2] O. Le Bihan, A. Joubert, D. Venditti, T. Tran, G. Ounoughene, B. Debray, S. Durécu, L. Le Coq, Characterization and reduction of particulate emissions from the incineration of wastes containing engineered NMs, Summary of the NanoFlueGas ADEME Project - Convention no 1181 C0088, (2014) 7 p..

[3] T. Walser, L.K. Limbach, R. Brogioli, E. Erismann, L. Flamigni, B. Hattendorf, M. Juchli, F. Krumeich, C. Ludwig, K. Prikopsky, M. Rossier, D. Saner, A. Sigg, S. Hellweg, D. Günther, W.J. Stark, Persistence of engineered nanoparticles in a municipal solid-waste incineration plant, Nat. Nanotechnol. 7 (2012) 520-524.

[4] A. Massari, M. Beggio, S. Hreglich, R. Marin, S. Zuin, Behavior of $\mathrm{TiO}_{2}$ nanoparticles during incineration of solid paint waste: a lab-scale test, Waste Manag. 34 (2014) 1897-1907.

[5] S. Derrough, G. Raffin, D. Locatelli, P. Nobile, C. Durand, Behaviour of nanoparticles during high temperature treatment (Incineration type), J. Phys. Conf. Ser. 429 (2013).

[6] E.P. Vejerano, E.C. Leon, A.L. Holder, L.C. Marr, Characterisation of particle emissions and fate of nanomaterials during incineration, Environ. Sci. Nano 1 (2014) 133-143.

[7] E.P. Vejerano, A.L. Holder, L.C. Marr, Emissions of polycyclic aromatic hydrocarbons, polychlorinated dibenzo-p-dioxins, and dibenzofurans from incineration of nanomaterials, Environ. Sci. Technol. 47 (2013) 4866-4874.

[8] G. Ounoughene, O. Le Bihan, C. Chivas-Joly, C. Motzkus, C. Longuet, B. Debray, A. Joubert, L. Le Coq, J.-M. Lopez-Cuesta, Behavior and fate of halloysite nanotubes (HNTs) when incinerating PA6/HNTs nanocomposite, Environ. Sci. Technol. 49 (2015) 5450-5457.

[9] N.C. Muller, J. Buha, J. Wang, A. Ulrich, B. Nowack, Modeling the flows of engineered nanomaterials during waste handling, Environ. Sci.: Processes Impacts 15 (2013) 251-259.

[10] D.-T. Tran, A. Joubert, D. Venditti, S. Durecu, T. Menier, O. Le Bihan, E. Fiani, L. Le Coq, Characterization of polymer wate containing nano-fillers prior its end-of-life treatment, Waste Biomass Valor, Springer, 2016, https://doi.org/10.1007/s16649 016-9757-0.

[11] B. Laubie, A. Ohannessian, V. Desjardin, P. Germain, Methodology to assess silicone (bio)degradation and its effects on microbial diversity, J. Polym. Environ. 20 (2012) 1019-1026.

[12] A. Colas, Silicones: preparation, properties and performance, Dow Corning Life Sciences, (2005).

[13] Y. Horii, K. Kannan, Survey of organosilicone compounds, including cyclic and linear siloxanes, in personal-care and household products, Arch. Environ. Contam. Toxicol. 55 (2008) 701-710.

[14] A.A. Turkin, M. Dutka, D. Vainchtein, S. Gersen, V.M. van Essen, P. Visser, A.V. Mokhov, H.B. Levinsky, J.Th.M. De Hosson, Deposition of $\mathrm{SiO}_{2}$ nanoparticles in heat exchanger during combustion of biogas, Appl. Energy 113 (2014) 1141-1148.

[15] B. Tansel, S.C. Surita, Oxidation of siloxanes during biogas combustion and nanotoxicity of Si-based particles released to the atmosphere, Environ. Toxicol. Pharmacol. 37 (2014) 166-173.

[16] R. Dewil, L. Appels, J. Baeyens, Energy use of biogas hampered by the presence of siloxanes, Energy Convers. Manage. 47 (2006) 1711-1722.

[17] M.J. Owen, Siloxane surface-activity, Adv. Chem. Ser. 224 (1990) 705-739.

[18] O. Hayashida, K. Oishi, A. Kashima, Silicone rubber composition having excellent heat resistance, EP 2 (554) (2013) 585.

[19] S. Hamdani, C. Longuet, D. Perrin, J.M. Lopez-Cuesta, F. Ganachaud, Flame retardancy of silicone-based materials, Polym. Degrad. Stab. 94 (2009) 465-495.

[20] G. Camino, S.M. Lomakin, M. Lageard, Thermal polydimethylsiloxane degradation. Part 2. The degradation mechanisms, Polymer 43 (2002) 2011-2015.

[21] G. Camino, S.M. Lomakin, M. Lazzaria, Polydimethylsiloxane thermal degradation Part 1. Kinetic aspects, Polymer 42 (2001) 2395-2402.

[22] Evonik Industries, Technical bulletin 11: Basic Characteristics and Applications of AEROSIL ${ }^{\oplus}$ products, TB 11-1-(7/2006).

[23] D. Napierska, L.C.J. Thomassen, D. Lison, J.A. Martens, P.H. Hoet, The nanosilica hazard: another variable entity, Part. Fibre Toxicol. 7 (2010) 1-32.

[24] C. Fruijtier Polloth, The toxicological mode of action and the safety of synthetic amorphous silica-a nanostructured material, Toxicology 11 (2012) 61-79.

[25] T. Kashiwagi, J.-R. Shields, R.-H. Harris Jr., R.D. Davis, Flame retardant mechanism of silica - effects of molecular weight of resin, J. Appl. Polym. Sci. 87 (2003) 1541-1553.

[26] G. Ounoughène, Etude des emissions liées à la decomposition thermique de nanocomposites: Application à l'incinération, $\mathrm{PhD}$, November 11th Ecole Nationale des Mines de Nantes-Université Nantes Angers Le Mans, 2015.

[27] Reference Document on Best Available Techniques for the Waste Treatments Industries, http://ied.ineris.fr/sites/default/files/files/wt_bref_0806.pdf, 2006 (Accessed 18 July 2016).

[28] J. Keskinen, K. Pietarinen, M. Lehtimaki, Electrical low pressure impactor, J. Aerosol Sci. 23 (1992) 353-360.

[29] G. Biskos, K. Reavell, N. Collings, Description and theoretical analysis of a differential mobility spectrometer, Aerosol Sci. Technol. 39 (2005) 527-541.

[30] J.P.R. Symonds, K.S.J. Reavell, J.S. Olfert, B.W. Campbell, S.J. Swift, Diesel soot mass calculation in real-time with a differential mobility spectrometer, Aerosol Sci. 38 (2007) 52-68.

[31] P.F. De Carlo, J.G. Slowik, D.R. Worsnop, P. Davidovits, J.L. Jimenez, Particle morphology and density characterization by combined mobility and aerodynamic diameter measurements, part 1: theory, Aerosol Sci. Technol. 38 (2004) 1185-1205.

[32] C. Chivas-Joly, F. Gaie-Levrel, C. Motzkus, S. Ducourtieux, A. Delvallée, F. De Lagos, S. Le Nevé, J. Gutierrez, J.-M. Lopez-Cuesta, Characterization of aerosols and fibers emitted from composite materials combustion, J. Hazard. Mater. 301 (2016) 153-162.

[33] B. R'Mili, O. Le Bihan, C. Dutouquet, O. Aguerre-Chariol, E. Frejafon, Particle sampling by TEM grid filtration, Aerosol Sci. Technol. 47 (2013) 767-775.

[34] G. Buscarino, V. Ardizzone, G. Vaccaro, F.M. Gelardi, Sintering process of amorphous $\mathrm{SiO} 2$ nanoparticles investigated by AFM, IR and Raman techniques, J. NonCryst. Solids 357 (2011) 1866-1870.

[35] P.-J. Temmerman, E. van Doren, E. Verleysen, Y. van der Stede, M.A.D. Francisco, J. Mast, J. Nano Biotechnol. 12 (2012) 10-24.

[36] D. Walter, Primary particles - agglomerates - aggregates, in: A. Hartwig (Ed.), Deutsche Forschungsgemeinschaft-Nanomaterials, Wiley-VCH, Weinheim, Germany, 2012.

[37] D. Bahloul-Hourlier, J. Latournerie, P. Dempsey, Reaction pathways during the thermal conversion of polysiloxane precursors into oxycarbide ceramics, J. Eur. Ceram. Soc. 25 (2005) 979-985.

[38] I.V. Schweigert, K.E.J. Lehtinen, M.J. Carrier, M.R. Zachariah, Structure and properties of silica nanoclusters at high temperature, Phys. Rev. B 65 (2002) 1-9.

[39] S. Dekkers, P. Krystek, R.J.B. Peters, D.P.K. Lankveld, B.G.H. Bokkers, P.H. van Hoeven-Arentzen, H. Bouwmeester, A.G. Oomen, Presence and risks of nanosilica in food products, Nanotoxicology 5 (2011) 393-405.

[40] L. Reijnders, The release of $\mathrm{TiO}_{2}$ and $\mathrm{SiO}_{2}$ nanoparticles from nanocomposites, Polym. Degrad. Stab. 94 (2009) 873-876. 